\title{
Effects of Salt Quenching Temperatures on Microstructure and Creep Properties of a PM Ni-based Superalloy
}

\author{
Jun Xie ${ }^{1}$, Sugui Tian ${ }^{1^{*}}$, Jiao Liu $^{1}$, Xiaoming Zhou ${ }^{2}$ \\ ${ }^{1}$ School of Materials Science and Engineering, Shenyang University of Technology, Shenyang 110870; China, \\ ${ }^{2}$ Beijing Institute of Aeronautical Materials, Beijing 100095, China \\ Email: "tiansugui2003@163.com
}

Received 2013

\begin{abstract}
By means of the microstructure observation and creep properties measurement, an investigation has been made into the influence of the salt quenching temperatures on the microstructure and creep property of FGH95 superalloy. The results shown that, after full heat treatment, a high volume of $\gamma^{\prime}$ phase and some granular carbide dispersedly precipitate in the matrix. Thereinto, as the molten salt temperature decreases from $650^{\circ} \mathrm{C}$ to $520^{\circ} \mathrm{C}$, the size of fine $\gamma^{\prime}$ phase in the alloy decrease gradually and the amount of carbides increase in the alloy. And the alloy quenched in molten salt at $520^{\circ} \mathrm{C}$ possesses better creep resistance due to the fact that there are more granular carbides precipitating in the alloy to enhance the grain strength. During creep, the deformation features of the alloy are that the configurations of stacking fault and slipping dislocations are activated in the alloy.
\end{abstract}

Keywords: FGH95 Ni-Based Alloy; Salt Quenching Temperature; Microstructure; Creep Property; Deformation Feature

\section{Introduction}

With the development of aviation industry, the service performance of aviation components is required to have a better reliability. Especially in turbine disk of aeroengine, it needs higher enduring temperature, carrying capacity and better stress rupture properties under the service condition [1-2]. With the alloying degree of traditional wrought superalloy increasing, the hot-workability of the alloy goes from bad to worse due to the in- homogeneous microstructure and serious segregation of elements in the alloy. However, the Ni-based powder superalloy is an excellent material used for preparing the high temperature rotating parts of the advanced aeroengine because of its advantages of fine grains, homogeneous microstructure, no macro-segregation in the ingot and so on [3-5].

FGH95 alloy is a precipitation-hardened PM Ni- based superalloy with a high fraction of $\gamma^{\prime}$ phase, and has higher tensile and yield strength at $650^{\circ} \mathrm{C}[6,7]$. FGH95 superalloy has a compact structure after hot isosatic pressing (HIP), here, there are coarse $\gamma^{\prime}$ phase precipitating along previous particle boundaries (PPB), and the microstructures of dendrite and recrystallization appear in the grain [8]. After the HIP alloy is heat treated by different technics, the alloy can obtain different microstructures $[9,10]$. Some researches show that different quenching technics (oil cooling and salt cooling) have an important effect on the microstructure and creep properties, and the "salt cooling" alloy possesses better stress rupture property ${ }^{[1]}$. But the influences of salt quenching temperatures on microstructure and creep properties of FGH95 alloy are still not clear.

In this paper, the FGH95 alloy is solution treated and quenched in the molten salt at different temperatures, and then aged. The creep properties of the alloy, cooled in molten salt at different temperatures, are measured under the condition of $650^{\circ} \mathrm{C}$ and $1034 \mathrm{MPa}$. Moreover, the microstructures of the alloy are observed by scanning electron microscopy (SEM) and transmission electron microscopy (TEM), and the influences of salt cooling temperature on microstructure and creep properties can be investigated.

\section{Experimental procedure}

The powder particles of FGH95 nickel-base superalloy with 150 meshes in size are put into a stainless steel can to pretreat at $1050^{\circ} \mathrm{C}$ for $4 \mathrm{~h}$. The can containing FGH95 powder particles is hot isostatic pressing (HIP) treated for $4 \mathrm{~h}$ under the conditions of $1150^{\circ} \mathrm{C}$ and $120 \mathrm{MPa}$ to form the ingot of the alloy. The chemical composition of FGH95 alloy is shown in Table 1. Moreover, the HIP treated alloy is solution treated at $1150^{\circ} \mathrm{C}$ for $1 \mathrm{~h}$, and 
then quenched in the molten salt at different temperatures $\left(520^{\circ} \mathrm{C}, 583^{\circ} \mathrm{C}\right.$ and $\left.650^{\circ} \mathrm{C}\right)$ for $15 \mathrm{mins}$, respectively. Finally, the quenched alloys are treated for twice aging $\left(870{ }^{\circ} \mathrm{C} \times 1 \mathrm{~h}+650{ }^{\circ} \mathrm{C} \times 24 \mathrm{~h}\right)$.

The ingot of FGH95 superalloy is cut into the specimens with the cross-section of $4.5 \mathrm{~mm} \times 2.5 \mathrm{~mm}$ and the gauge length of $20 \mathrm{~mm}$. Uniaxial constant load tensile testing is performed, in a GWT504 model creep testing machine, for measuring the creep properties of the alloy under the conditions of $1034 \mathrm{MPa}$ and $650^{\circ} \mathrm{C}$. The microstructures of the alloy after different heat treatment are observed by SEM and TEM, so that the effects of salt quenching temperatures on microstructure and creep properties of the alloy can be investigated.

\section{Experimental Results and Analysis}

\subsection{Influence of Salt Quenching Temperatures on Microstructure of the Alloy}

The SEM microstructures of solution treated alloy after quenching in the molten salt at different temperatures $\left(520^{\circ} \mathrm{C}, 583^{\circ} \mathrm{C}\right.$ and $\left.650^{\circ} \mathrm{C}\right)$ and aging are shown in Figure 1, respectively. Here, after quenching in molten salt at $520^{\circ} \mathrm{C}$, the grain size is about $10 \mu \mathrm{m} \sim 25 \mu \mathrm{m}$, and there is some coarse $\gamma^{\prime}$ phase discontinuously distributing along the grain boundaries as marked with short arrow in Figure 1(a). Moreover, many white carbide particles ${ }^{[12]}$ dispersedly precipitate in the alloy as marked with long arrow in Figure 1(a).

As the salt quenching temperature increases to $583^{\circ} \mathrm{C}$, there are still some coarse $\gamma^{\prime}$ phase exsiting in the boundary regions, and the amoount of carbide particles decreases gradually as marked with the short arrow in Figure 1(b), and the twinning appears in the grain as marked with the long arrow in Figure 1(b). As the molten salt temperature further enhacnes to $650^{\circ} \mathrm{C}$, the coarse $\gamma^{\prime}$ phase with $1 \sim 2.5 \mu \mathrm{m}$ in size appears in the grain boundary, and the amount of carbide particles further decrease as shown Figure 1(c).

The TEM microstructures of fine $\gamma^{\prime}$ phase precipitated in the alloy quenched in the molten salt at different temperatures and aged are shown in Figure 2. After

Table 1. Chemical composition of FGH95 alloy (mass fraction, \%).

\begin{tabular}{cccccccccc}
\hline $\mathrm{C}$ & $\mathrm{B}$ & $\mathrm{Cr}$ & $\mathrm{Co}$ & $\mathrm{Al}$ & $\mathrm{Ti}$ & $\mathrm{W}$ & $\mathrm{Mo}$ & $\mathrm{Nb}$ & $\mathrm{Ni}$ \\
\hline 0.060 & 0.012 & 12.98 & 8.00 & 3.48 & 2.55 & 3.40 & 3.40 & 3.50 & Bal \\
\hline
\end{tabular}
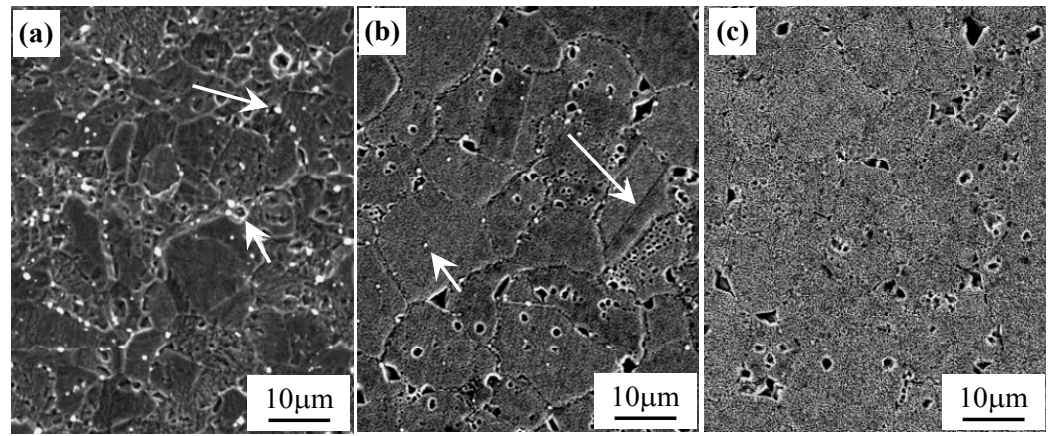

Figure 1. SEM microstructures of the solution treated alloy after quenching in molten salt at different temperatures and aged. (a) $520^{\circ} \mathrm{C}$, (b) $583^{\circ} \mathrm{C}$, (c) $650{ }^{\circ} \mathrm{C}$.
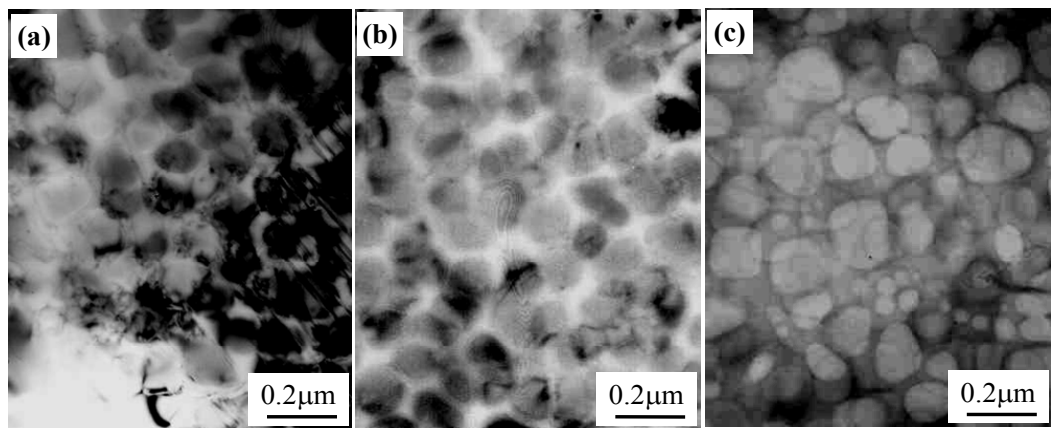

Figure 2. Morphology of the fine $\gamma^{\prime}$ phase precipitated in the alloy after quenched in melting salt at different temperatures and aged. (a) $520^{\circ} \mathrm{C}$, (b) $583^{\circ} \mathrm{C}$, (c) $650^{\circ} \mathrm{C}$ 
quenching in the molten salt at $520^{\circ} \mathrm{C}$, the fine $\gamma^{\prime}$ phase with $0.1 \sim 0.16 \mu \mathrm{m}$ size dispersedly precipitates in the alloy as shown in Figure 2(a). As the temperature of the molten salt increases to $583^{\circ} \mathrm{C}$, the fine $\gamma^{\prime}$ phase grows up slightly, and its size is about $0.12 \sim 0.18 \mu \mathrm{m}$ as shown in Figure 2(b). As the molten salt temperature further increases to $650^{\circ} \mathrm{C}$, the fine $\gamma^{\prime}$ phase with the size of $0.15 \sim$ $0.2 \mu \mathrm{m}$ appears in the grain, as shown in Figure 2(c). This indicates that the size of $\gamma^{\prime}$ phase precipitated in the alloys after different quenching treatments increases slightly as the salt quenching temperature increases, therefore, the size of $\gamma^{\prime}$ phase in the alloy can be adjusted by quenching in molten salt at different temperatures.

\subsection{Influence of Salt Quenching Temperatures on Creep Properties of the Alloy}

After the alloy quenched at molten salt at different temperatures and aged, the creep curves of the alloys are measured under the condition of $650^{\circ} \mathrm{C} / 1034 \mathrm{MPa}$, as shown in Figure 3.

Here, when the alloy is quenched in molten salt at $520^{\circ} \mathrm{C}$, the alloy possesses the lowest steady strain rate about $0.00654 \% / \mathrm{h}$ as illustrated by the curve 1 in Figure 3, and its creep lifetime of the alloy is about $70 \mathrm{~h}$. As the molten salt temperature increases to $583^{\circ} \mathrm{C}$, the creep curve of the alloy is marked with number 2 in Figure 3, which indicates that the strain rate of the alloy is measured to $0.00789 \% / \mathrm{h}$ during steady creep stage, and its creep lifetime decreases to $67 \mathrm{~h}$. The curve of the alloy quenched in molten salt at $650^{\circ} \mathrm{C}$ is marked with number 3 in Figure 3, illustrating that the steady strain rate of the alloy further increases to $0.0151 \% / \mathrm{h}$, and the creep lifetime of the alloy further decreases to $37.2 \mathrm{~h}$. This indicated that the alloy cooled in the molten salt at lower temperature possesses longer creep lifetime.

\subsection{The Deformed Features of FGH95 Alloy}

After the solution treated alloy is quenched in the molten salt at $520^{\circ} \mathrm{C}$ and aged, the TEM microstructures of the alloy crept to fracture are shown in Figure 4.

In the local region of the fracture alloy, the configuration of dislocation network appears in the alloy as marked with letter $A$ in Figure 4(a). In addition, there are fine carbide particles precipitating in the grain as marked with the white arrow in Figure 4(a), and the deformed dislocations slip in the matrix and pile up near the carbide particles as marked with the black arrow. This indicates that the carbide particles can hinder the dislocation movement effectively to enhance the creep resistance of the alloy.

In another region of the fracture alloy, it is clearly seen that the stacking fault appears in the alloy as marked with the arrow in Figure 4(b), and there are some deformed dislocations tangling up near the stacking fault as mark with letter B in Figure 4(b), which indicates that the stacking fault can hinder the dislocation slipping in the matrix. Figure 4(c) is another local region of the alloy crept for $70 \mathrm{~h}$ to fracture, thereinto, the microstructure of trigeminal grain boundaries is marked by the white arrow in Figure 4(c), and some granular carbides discontinuously

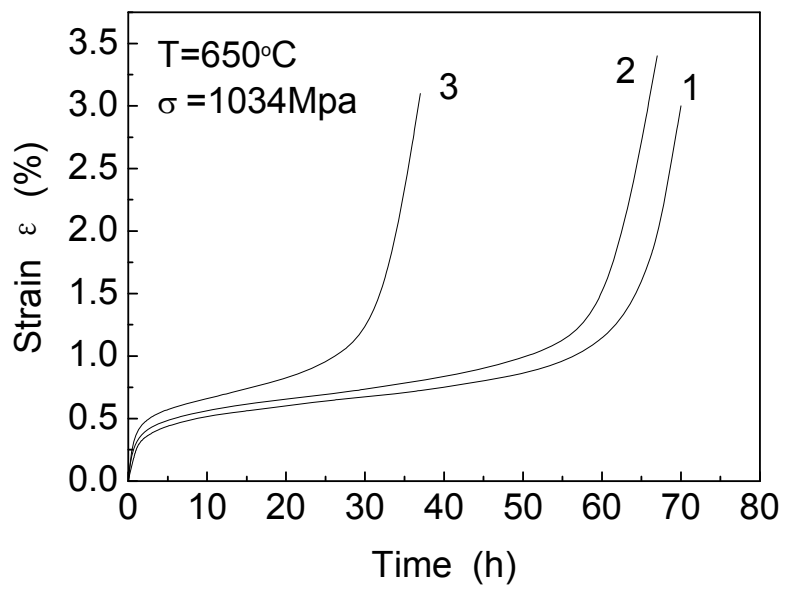

Figure 3. Creep curves of the alloy measured under the condition of $650^{\circ} \mathrm{C}$ and $1034 \mathrm{MPa}$.

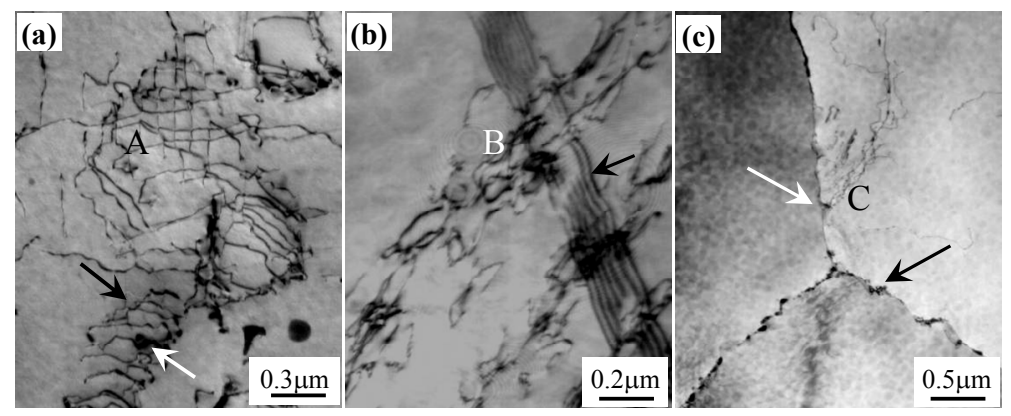

Figure 4. After solution treatment and quenching in molten salt at $520^{\circ} \mathrm{C}$, TEM microstructure of the alloy crept to fracture under the applied stress of $1034 \mathrm{MPa}$ at $650^{\circ} \mathrm{C}$. (a) Dislocation network in the alloy; (b) the stacking fault appeared in the alloy, (c) slipping dislocations ending at grain boundary. 
distribute along the boundaries as marked with the black arrow in Figure 4(c), and the slipping dislocations are end at the grain boundary as marked by letter $\mathrm{C}$, which indicates that the grain boundaries can hinder the dislocation movement during creep.

\section{Discussion}

Because the solid-solution temperature $\left(1150^{\circ} \mathrm{C}\right)$ was lower than the melting point of $\gamma^{\prime}$ phase $\left(\mathrm{T}_{\gamma^{\prime}}=1160^{\circ} \mathrm{C}^{[13]}\right)$, the coarse $\gamma^{\prime}$ phase can't be dissolved completely in the alloy, so that some coarse $\gamma^{\prime}$ phase discontinuously distributes along the boundary regions of the alloy after full heat treatment, as shown in Figure 1. When the solution treated alloy is quenched in the molten salt at $520^{\circ} \mathrm{C}$, the matrix of the alloy can obtain higher saturation due to the higher cooling rate for the alloy, which causes the inner-stress existing in the matrix of the alloy ${ }^{[14]}$. Moreover, because the elements $(\mathrm{Nb}, \mathrm{Ti}$ et al) with bigger atom radius can't be diffused enough during quenching in the molten salt, the rich regions of solute are formed in the matrix [15]. The facts mentioned above provide the advantage conditions for the carbide particles precipitating in the alloy during quenching and aging. Therefore, there are more granular carbides precipitating in the alloy quenched in molten salt at lower temperatures, as shown in Figure 1. Besides due to the fact that the cooling rate of the alloy decreases as the molten salt temperature increases, the diffusion degree of the alloy elements is sufficient comparatively during quenching in the molten salt at $650^{\circ} \mathrm{C}$. Therefore, the alloy quenched in the molten salt at $650^{\circ} \mathrm{C}$ can obtain the bigger $\gamma^{\prime}$ phase in size as shown in Figure 2(c).

After the solution treated alloy is quenched in molten salt at $520^{\circ} \mathrm{C}$ and aged, there is a high volume fraction of $\gamma^{\prime}$ phase with smaller size precipitating in the grain, and more carbide particles discontinuously distribute in the grain and along the boundaries (as shown in Figure 1(a)), which can improve the grain strength and hinder the dislocation movement during creep. Besides the stacking fault formed in the alloy can restrain the dislocation slipping as shown in Figure 4(b). The facts mentioned above are the important factors for the alloy possessing the higher creep resistance.

\section{Conclusions}

1) After full heat treatment, some coarse $\gamma^{\prime}$ phase discontinuously distribute in the boundary regions, and a high volume fraction of $\gamma^{\prime}$ phase and some carbide particles precipitate in the alloy. Here, as the salt quenching temperature increases from $650^{\circ} \mathrm{C}$ to $520^{\circ} \mathrm{C}$, the size of fine $\gamma^{\prime}$ phase increases slightly, but the amount of granular carbide decrease in the alloy gradually.
2) The alloy quenched in molten salt at lower temperature possesses a better match on the size and distribution of $\gamma^{\prime}$ phase and carbides, which can enhance the grain strength for the alloy possessing a better creep resistance. The deformed features of the alloy are that the deformed dislocations slip in the matrix and stacking fault forms in the alloy during creep.

\section{REFERENCES}

[1] Hu Ben-fu, Tian Gao-feng, Jia Cheng-chang, et al. Development in double-properties turbine disk of $\mathrm{P} / \mathrm{M}$ superalloy [J]. Journal of Aeronautical Materials, 2007, 27(4), 80 84.

[2] Zainul H.. Development of heat-treatment process for a $\mathrm{P} / \mathrm{M}$ superalloy for turbine blades[J]. Materials and Design, 2007, 28, 1664 1667.

[3] Raujol S., Pettinari F., Locq D., etc. Creep straining micro-mechanisms in a power -metallurgical nickel-based superalloy [J]. Mater Sci Eng A 2004; 387 389: $678 \sim 682$.

[4] CHEN Huan-ming, HU Be-fu, LI Hui-ying, SONG Duo. Pr-heat treatment of PREP FGH95 superalloy podwers[J]. The Chinese Journal of Nonferrous Metals, 2003, 13(3): $554-559$.

[5] Xie X. S., Zhang L. N., Zhang M. C., et al. Micro-mechanical behavior study of non-metallic inclusions in $\mathrm{P} / \mathrm{M}$ disk superalloy Rene'95[C]. Superalloys, TMS, 2004, pp. 451-458.

[6] Lu Z. Z., Liu C. L., Yue Z. F.. Probabilistic safe analysis of the working life of a powder metallurgical turbine $\operatorname{disc}[\mathrm{J}]$. Materials Science and Engineering A, 2005, 395: $153 \sim 159$.

[7] Li Hong-yu, Song Xi-ping, Wang Yan-li, Chen Guo-liang. Stability of $\gamma^{\prime}$ phase in FGH95 superalloy[J]. Rare Metal Materials and Engineering, 2009, 38(1): 64 - 67.

[8] Liu Dong-ming, Zhang Ying, Liu Pei-ying, Zhang Yi-wen. Study on the PPB defect of P/M superalloy FGH95 [J]. Powder Metallurgy Industry, 2006, 16(3), 1 5.

[9] Tian S. G., Liu Y., Zhao Z. G., et al. Creep behaviors of FGH95 Powder Ni-Base Superalloy [J]. Chinese Journal of Aeronautics, 2009, 22(4), $444 \sim 448$.

[10] Guo Wei-ming, Zhang Feng-ge, Feng Di, et al. Effects of producing process on microstructure and properties of FGH95 P/M superalloy [J]. Powder Metallurgy Industry, 2001, 11(5): 7 12.

[11] TIAN Su-gui, XIE Jun, ZHOU Xiao-ming, QIAN Ben-jiang, LUN Jian-wei, YU Li-li, WANG Wu-xiang. Effects of quenching technics on microstructure and creep properties of FGH95 superalloy[J]. The Chinese Journal of Nonferrous Metals, 2010, 20(5): 852 - 858 .

[12] TIAN Su-gui, LIU Yang, ZHAO Zhong-gang, BAO Xian-yu. Microstructure and creep features of FGH95 powder nickel base superalloy after heat treatment[J]. Journal of Aeronautical Materials, 2009, 29(6): 33 - 37. 
[13] ZHANG Yi-wen, ZHANG Ying, ZHANG Feng-ge, YANG Shi-zhong. The effect of solution temperature on properties of FGH95 PM superalloy manufactured by PREP $[J]$. Transactions of Materials and Heat Treatment, 2002, 23(3): $72-75$.

[14] Youdelis W V, Kwon O. Carbide phases in cobalt base superalloy: role of nucleation entropy in refinement $[\mathrm{J}]$. Metal Science, 1983, 17(8): 379 381.

[15] Hu Ben-fu, Chen Huan-ming, Song Du, Li hui-ying. The effect of pre-heating on carbide precipitates in FGH95 superalloy powders prepared by PREP [J]. Acta Metallurgica Sinica, 2003, 39(5): 470 475. 